munda. Doch mögen die letzgenannten Unterschiede auf individueller Abänderung beruhen. -

Zwei weitere Bälge der Waibelschen Sammlung können wegen ihres äufserst mangelhaften Erhaltungszustandes nur unsicher bestimmt werden:

39. eine Batis, die vermutlich zu pririt gehört, und

40. eine Beutelmeise (Kemiz sp.).

\title{
Zum heurigen Durchzug des Seidenschwanzes 1920/21.
}

\section{Von V. V. Tschusi zu Schmidhoffen.}

Das Auftreten des Seidenschwanzes in Mitteleuropa ist keine Seltenheit, doch handelt es sich da zumeist um kleine Gesellschaften, die besonders im Osten öfters zur Beobachtung gelangen und da oft sehr weit nach Süden vordringen. Im heurigen Jahre scheint wieder ein ganz bcträchtlicher Durchzug stattgefunden zu haben, dessen Ausbreitung eine ganz bedeutende gewesen sein dürfte. Die gehabte Absicht, auch diesen Zug in seiner Gänze zu bearbeiten, scheiterte an dem Umstande, dals der wissenschaftliche Verkehr mit den Deutschen und DeutschOesterreichischen Randstaaten bedauerlicherweise noch sehr im Argen liegt. Wir sind, da über den Südzug nur dürftige Nachrichten vorliegen, über den Zugbeginn ganz ungenügend orientiert, wissen daher nicht, wann er seinen Anfang nahm und ebenso nicht, woher er erfolgte; nur über seine Entfaltung und das Abflauen des Zuges, sowie sein allmähliches Erlöschen sind wir einigermalsen unterrichtet. Da die ersten Nachrichten über das Erscheinen von Seidenschwänzen aus der Schweiz erfolgten, könnnte das den Anschein erwecken, dafs die Fremdlinge den Weg zu uns aus dem Westen genommen hätten. Das wäre aber ein Trugschlufs, denn die Schweiz sah nur eine verhältnismälsig kleine Zahl im Land, und so müssen die grofsen Mengen, welche besonders in Mähren und auch in Schlesien auftraten, wohl aus dem Osten hergekommen sein. Völlige Klarheit darüber wird sich wohl später ergeben, wenn im Interesse der Wissenschaft, für welche es keine politischen Grenzen geben soll und darf, ein freier Verkehr wieder Platz gegriffen hat.

Die uns vorliegenden Daten sind folgende:

\section{Schweiz.}

W attwiel (Toggenburg). Nach Dr. J. Winkteler am 21. November 1920 ein Schwarm, der bis Ende Dezember gesichtet wurde [Orn. Beob. XVIII, 1920/21. Nr. 4. p. 62, Nr. 5. p. 79]. Ende Februar 1921 meldet F. Matchys je einen von $\mathrm{H}$ e im iswil und Dü rre n r oth (Bern) [Orn. Beob. XVIII, 1920/21. 


\section{$2 \mathrm{BHL}$ Biodiversity Heritage Library}

Tschusi zu Schmidhoffen, Victor von. 1922. "Zum heurigen Durchzug des Seidenschwanzes 1920/21." Journal fu

r Ornithologie 70, 49-49. https://doi.org/10.1007/bf02540390.

View This Item Online: https://www.biodiversitylibrary.org/item/215787

DOI: https://doi.org/10.1007/bf02540390

Permalink: https://www.biodiversitylibrary.org/partpdf/210630

\section{Holding Institution}

Smithsonian Libraries

\section{Sponsored by}

Biodiversity Heritage Library

\section{Copyright \& Reuse}

Copyright Status: Not in copyright. The BHL knows of no copyright restrictions on this item.

This document was created from content at the Biodiversity Heritage Library, the world's largest open access digital library for biodiversity literature and archives. Visit BHL at https://www.biodiversitylibrary.org. 